\title{
A Study to Assess Hand Hygiene Knowledge and Practices among Health Care Workers in a Teaching Hospital in Ghana
}

\author{
Immanuel Amissah, BSc, MD ${ }^{1}$, Soziema Salia ${ }^{2}$, MBChB, Joshua Panyin Craymah, MSc $^{3}$ \\ ${ }^{1,2,3}$ Department of Internal Medicine \& Therapeutics,University of Cape Coast School of Medical Sciences, Cape Coast, Ghana
}

\begin{abstract}
Background: Despite widespread evidence that proper hand hygiene practices is the simplest and most-effective intervention to reduce transmission of hospital-acquired infections, healthcare workers adherence to proper hand hygiene practices remains poor. This study was to 1) assess the knowledge of proper hand hygiene among health care workers according to WHO guidelines, 2) to assess hand hygiene practices among healthcare workers at the hospital, 3)to assess any correlations between knowledge of hand hygiene and professional type; and department of health care provider and 4) to assess factors that hinder proper hand hygiene practices. Methods: The study was conducted at the Cape Coast Teaching Hospital from January, 2016 through April, 2016. A total of 130 healthcare workers participated in the study. A cross-sectional survey was conducted using a self-administered questionnaire based on the hand hygiene guidelines by the World Health Organization (WHO). Results: Majority of the respondents (51.2\%) knowledge on hand hygiene was fair.Compliance to proper hand hygiene practices was hampered by heavy patient load (33.5\%), forgetfulness (23.6\%), inadequate water (21.9\%), lack of clean towels (15.1\%), absence of air dryer (14.0\%).The techniques commonly used for hand hygiene reported were the use of cold running water (27.3\%), use of alcohol-based hand rub (22.9\%). Only 18 (5.3\%) used warm running water.Hand drying technique used included: use of common towels (30.3\%), use of personnel handkerchiefs (21.5\%), allowing hands to dry on their own (19.3\%), use of disposable towels (10.9\%).Also there was a statistically significant correlation between healthcare workers professional status and knowledge on hand hygiene (p=0.005). Conclusion: This study showed that knowledge in hand hygiene practices was found to be fair, with heavy patient load, forgetfulness and unavailability of water and lack of clean towels being the major contributing factors hampering proper hand hygiene practices. Also low patronage for alcohol-based hand rubs was found. A hospital-wide awareness program aiming at healthcare workers and adoption of alcohol-based hand rubs at the point of care can help improve compliance to hand hygiene.
\end{abstract}

Keywords: Knowledge, hand hygiene, healthcare workers, Cape Coast, Ghana

\section{Introduction}

Hand hygiene has become a major issue in health care settings due to the high incidence of Health care associated infections (HCAIs), also known as nosocomial infections. Despite widespread evidence that hand hygiene is the simplest and most cost-effective intervention to reduce transmission of hospital-acquired infections (Pittet et al., 2000; Trick et al.,2007; Girou et al., 2006; Ho et al., 2012; Grayson et al., 2008; Grayson et al., 2011; Biddle et al.,2009), physicians' adherence to hand-hygiene practices remains consistently poor (Pittet et al.,2000; Danchaivijtr et al., 2005; Harris et al.,2000; Patarakul et al.,2005). Notable factors for poor compliance include hand irritation(Akyol $\mathrm{AD}, 2007)$, inaccessibility or shortage of hand-washing equipments, dense working conditions, (Akyol AD ,2007; Sax et al.,2005; Pittet et al.,2004) and poor knowledge( Danchaivijtr et al., 2005; Sax et al.,2005).

Health-care associated infections continue to pose aserious threat of increasing mortality and morbidity among hospitalized patients and World Health Organization reportsthat at anytime, over 1.4 million people world- wide sufferfrom infections acquired in health-care settings (WHO,2005).In developed countries, HCAIs have been reported to affect $5 \%-15 \%$ of hospitalized patients and $9 \%$ $37 \%$ of those admitted to intensive care units (Vincent JL,2003), while in developing countries where reliable data on HCAIs are limited, prevalence rates have been estimated to be between $14.8 \%$ and $19.1 \%$ (Gosling et al.,2003; Faria et al.,2007; Kallel et al.,2005; Jroundi et al.,2007).
Organisms that cause nosocomial infections are mostcommonly transmitted by the hands of healthcare workers(Kusachi et al., 2006).Hand hygiene practices may also vary among professional groups(Rao MH,2006; Pittet et al.,2004; Suchitra\& Devi, 2007).However, most relevant studies agree that type and availability of facilities have a significant effect on hand hygiene ( Samuel et al.,2005; Boyce JM,2000).

Formal written guidelines on hand hygiene practices in hospitals have been developed by the Centers for Disease Control and Prevention (CDC) and World Health Organization (WHO). According to the World Health Organization(WHO,2005) the indications for hand hygiene can be merged into five (5) moments during health care delivery. Adequate knowledge and recognition of these moments are the pillars for effective hand hygiene. Therefore, it is possible to prevent health care associated infections by cross-transmission via hands if health care providers promptly identify these moments and comply with hand hygiene actions. These five moments that call for the use of hand hygiene include the moment before touching a patient, before performing aseptic and clean procedures, after being at risk of exposure to body fluids, after touching a patient, and after touching patient surroundings.

Hospital-acquired infection rates are also known to be highest in teaching hospitals (Samuel et al., 2005). In Ghana, a cross-sectional observational study at the Komfo Anokye Teaching Hospital in Kumasi byOwusu-Oforiet al (2010) 


\section{International Journal of Science and Research (IJSR) \\ ISSN (Online): 2319-7064 \\ Index Copernicus Value (2013): 6.14 | Impact Factor (2015): 6.391}

indicated that the most commonly identified barriers to hand hygiene by health workers were limited resources and lack of knowledge on appropriate times to perform hand washing or rubbing. A study conducted in 2009, at the Neonatal Intensive Care Unit (NICU) of the Department of Child Health in the Korle-Bu Teaching Hospital, Ghana by Asare et al(2009) indicated that hand hygiene compliance of physicians and nurses in that unit was low. Another study in Ghana by Yawson and Hesse (2013) showed that carerelated hand hygiene $(\mathrm{HH})$ compliance of doctors and nurses was low and basic $\mathrm{HH}$ resources were deficient in all 15 service centres that were studied. In that sttdy, care-related $\mathrm{HH}$ compliance among doctors ranged from $9.2 \%$ to $57 \%$ and $9.6 \%$ to $54 \%$ among nurses and $\mathrm{HH}$ compliance was higher when risk was perceived to be higher (i.e., in the emergency and wound dressing/treatment rooms and labour wards). In that same study, facilities for $\mathrm{HH}$, particularly alcohol hand rub and liquid soap dispensers were shown to be deficient. No such studies has been conducted at the Cape Coast teaching hospital, Ghana. Therefore, the aim of this study was to assess Hand Hygiene Knowledge and practices among health care providers at the Cape Coast teaching hospital, Ghana. The objectives of the study was to 1)assess the knowledge of proper hand hygiene among health care workers according to WHO guidelines, 2)to assess hand hygiene practices among healthcare workers at the hospital, 3) to assess any correlations between knowledge of proper hand hygiene and professional type;department of health care provider, 4)to assess factors that hinder proper hand hygiene practices.

\section{Methodology}

\section{Setting}

The study was conducted between January 2016 through April 2016 at the Cape Coast Teaching Hospital of Ghana. The Cape Coast teachinghospital is a tertiary health facility that provides a wide range of specialist services to the people in the Central region of Ghana as well as those in the neighboring region.

\section{Study Population}

Healthcare workers included in the study were: houseofficers, medical officers, resident doctors, specialist/ consultants, nurses, ward assistants, midwives, physiotherapist, anesthetists, $\mathrm{x}$-ray technologist and laboratory scientists who works at the hospital at the time of the study. All the health care providers working at the hospital at the time of the study were eligible for participation in the study. Those health care providers who were on leave during the data collection period were excluded.

\section{Study design}

The research design wasa cross sectional descriptive study..

\section{Sampling method}

Cluster sampling technique was used to recruit participants. Each ward in the hospital was visited thrice a week during the morning, afternoon and evening shift to distribute questionnaires to the health care workers on duty at that particular shift after obtaining informed consent. Departmental Clinical meetings were also used as clusters to reach doctors, while the laboratory was also visited during the morning, afternoon and evening shift. Potential respondents were given questionnaires to be returned through a designated colleague.

\section{Data collection}

A structured,self-administered questionnaire with both openended and close-ended questions were used to collect data. The questionnaire had three sections: section one wason the personal data and work history of each participant; section two assess the knowledge of participants on hand hygiene; and section three assess the hand hygiene practices among participants and the facilities available for hand hygiene in the hospital and the factors influencing hand hygiene practice in the hospital. Knowledge was assessed using the WHO's hand hygiene questionnaire for health care workers. This proforma of 25 questions includes multiple choice and 'yes' or 'no' questions. The knowledge of hand hygiene was scored as follows: each correct response was given one (1) point and each wrong response given a score zero (0). The maximum score will be 25 marks. The total score for each respondent was expressed as a percentage of the maximum score. Respondents were then categorized into those with poor knowledge $(<50 \%)$, fair knowledge (50-69.9\%) and good knowledge $(>70 \%)$. Hand hygiene practice was assessed by another self-structured questionnaire consisting of 13 questions.

\section{Ethical Clearance}

Ethical clearance was sought from the University of Cape Coast Institutional review board (UCCIRB/CHAS/2015/37). Approval was also sought from management of the Cape Coast Teaching hospital. Written informed consent was obtained from participants and confidentiality was ensured throughout the study.

\section{Data analysis}

Data obtained from the study wasanalyzed using the SPSS software version 20. Each completed questionnaire waschecked visually for completeness before fed to the computer.Descriptive statistics was used to calculate percentages for each of the responses given. Chi-square test was used to compare the percentage of correct responses among health care providers, and department. A P value less than 0.05 was considered significant.

\section{Results}

\subsection{Characteristics of Respondents'}

A total of 130 healthcare workers filled out the questionnaire, the majority of which $54(41.9 \%)$ were nurses, $21(16.3 \%)$ were houseofficers, 13 (10.1\%)were midwives and $10(7.8 \%)$ were medical officers. Majority (66.4\%) were within the $20-29$ age-group and $62.3 \%$ were females and $37.7 \%$ were males. Majority of the respondents' were from the following departments: emergency (18), Paediatrics (18), OPD (18), Obstetrics (15), laboratory (11). Majority $(65.9 \%)$ had $1-5$ years of working experience and more than half of the respondents' $(77.3 \%)$ have had training in hand hygiene. 


\section{International Journal of Science and Research (IJSR) \\ ISSN (Online): 2319-7064 \\ Index Copernicus Value (2013): 6.14 | Impact Factor (2015): 6.391}

\subsection{Knowledge on Hand Hygiene by Respondents'}

Table 2 and 3 demonstrates knowledge on hand hygiene by respondents' using the WHO hand hygiene questionnaire for healthcare workers. Only $10(8.7 \%)$ of the respondents' knew that the minimal time needed for alcohol-based hand rub to kill germs should be at least 20s. Majority of the respondents' knew that hand hygiene should be performed before touching a patient $(87.7 \%)$ and after touching a patient $(89.4 \%)$ respectively.

Also majority $(86.6 \%)$ knew that hand rubbing is not more effective against germs than handwashing. Less than half of the respondents' were aware of the hand hygiene method needed before giving an injection (39.4\%) and after making a patient's bed $(20.5 \%)$. Majority $(>80 \%)$ were aware that the following should be avoided as is associated with increased likelihood of colonisation of hands with harmful germs: wearing jewellery, damaged skin and artificial fingernails. The overall knowledge score computed showed that $29.5 \%$ of the respondents had poor knowledge, $51.2 \%$ had fair knowledge and $19.3 \%$ had good knowledge.

\subsection{Self-reported hand hygiene practices by Respondents'}

Table 4 and 5 shows hand hygiene practices reported by respondents'. Less than half $(31.1 \%)$ does not believe that infection prevention notices reminds them of hand hygiene. Also about $32.2 \%$ believes that wearing gloves sometimes reduces the need for hand hygiene. Majority of the respondents $(>70 \%)$ always washes hands after defecating, before and after meals. Top four (4) factors influencing hand hygiene practices included: inadequate water $(21.9 \%)$; lack of clean towels (15.1\%); lack of air dryer (14.0\%) and absence of detergent (13.0\%). Top three (3) reasons for not practicing hand hygiene included: heavy patient load (33.5\%); forgetfulness (23.6\%) and lack of time (17.9\%).

Techniques commonly used by respondents' for hand hygiene are the use of cold running water $(27.3 \%)$, use of alcohol-based hand rub (22.9\%). Only 18 (5.3\%) were using warm running water. Hand drying technique used included: use of common towels (30.3\%); use of personnel handkerchiefs $50(21.5 \%)$; allow hands to dry on their own $46(19.3 \%)$, use of disposable towels $25(10.9 \%)$.
3.4 Association between respondents' Professional status, their department and their hand hygiene knowledge score.

From table 6, the professional status of the healthcare worker was significantly associated with hand hygiene knowledge score $(\mathrm{P}=0.005)$, but not correlated to their departments $(\mathrm{P}=0.390)$.

Table 1: Socio-demographic characteristics of respondents'

\begin{tabular}{|c|c|c|}
\hline Characteristics & Frequency $(N)$ & Percent (\%) \\
\hline \multicolumn{3}{|l|}{ Age } \\
\hline $20-29$ & 73 & 56.2 \\
\hline $30-39$ & 36 & 27.7 \\
\hline $40-49$ & 17 & 13.1 \\
\hline $50-59$ & 2 & 1.5 \\
\hline $60+$ & 2 & 1.5 \\
\hline \multicolumn{3}{|l|}{ Gender } \\
\hline Male & 49 & 37.7 \\
\hline Female & 81 & 62.3 \\
\hline \multicolumn{3}{|l|}{ Professional status } \\
\hline Nurses & 54 & 41.9 \\
\hline House officer & 21 & 16.3 \\
\hline Midwife & 13 & 10.1 \\
\hline Medical officer & 10 & 7.8 \\
\hline Specialist/Consultant & 3 & 2.3 \\
\hline Lab Scientist & 9 & 7.0 \\
\hline Ward Assistant & 6 & 4.7 \\
\hline Physiotherapist & 4 & 3.1 \\
\hline Anaesthetist & 2 & 1.6 \\
\hline Other & 7 & 5.4 \\
\hline \multicolumn{3}{|l|}{ Departments } \\
\hline Internal medicine & 3 & 2.3 \\
\hline Surgery & 12 & 9.2 \\
\hline $\mathrm{ICU}$ & 5 & 3.8 \\
\hline Mixed Medical/Surgical & 10 & 7.7 \\
\hline Emergency & 18 & 13.8 \\
\hline Obstetrics & 15 & 11.5 \\
\hline Paediatrics & 18 & 13.8 \\
\hline Laboratory & 11 & 8.5 \\
\hline Outpatient Department & 18 & 13.8 \\
\hline Others & 20 & 15.4 \\
\hline \multicolumn{3}{|l|}{ Years of working experience } \\
\hline $1-5$ years & 85 & 65.9 \\
\hline $6-10$ years & 27 & 20.9 \\
\hline$>10$ years & 17 & 13.2 \\
\hline \multicolumn{3}{|l|}{ Training on hand hygiene } \\
\hline Yes & 99 & 77.3 \\
\hline No & 29 & 22.7 \\
\hline
\end{tabular}




\section{International Journal of Science and Research (IJSR) \\ ISSN (Online): 2319-7064 \\ Index Copernicus Value (2013): 6.14 | Impact Factor (2015): 6.391}

Table 2: Knowledge of Hand Hygiene Among Respondents'

Knowledge on hand hygiene practices (correct responses in brackets)

1.Which of the following is the main route of cross transmission of potentially harmful germs between patients in a health-care facility?

(Health-care workers hands when not clean) 69

2.What is the most frequent source of germs responsible for health care- associated infections?

(Germs already present on or within patient)

\begin{tabular}{|l|l|}
\hline 34 & 27.4 \\
\hline
\end{tabular}

Which of the following hand hygiene actions prevent transmission of germs to the patient?

3.Before touching a patient (Yes)

4.Immediately after risk of body fluid exposure (Yes)

5.Immediately before a clean/aseptic procedure $(\mathrm{No})$

6.After exposure to the immediate surroundings of a patient (Yes)

\begin{tabular}{|l|l}
\hline 100 & 87.7 \\
\hline 84 & 83.2 \\
\hline 93 & 91.2 \\
\hline 75 & 78.1 \\
\hline
\end{tabular}

Which of the following hand hygiene actions prevents transmission of germs to the healthcare worker?

7.After touching a patient (Yes)

8.Immediately after risk of body fluid exposure (Yes)

9.Immediately before a clean/aseptic procedure ( $\mathrm{No})$

10.After exposure to the immediate surroundings of a patient (Yes)

\begin{tabular}{l|r|}
101 & 89.4 \\
\hline 88 & 88.9
\end{tabular}

\begin{tabular}{l|r}
88 & 88.9 \\
\hline 30 & 31.3
\end{tabular}

\begin{tabular}{l|l}
30 & 31.3 \\
\hline 75 & 78.1
\end{tabular}

Which of the following statements on alcohol-based hand rub and handwashingwith soap and water are true

11.Hand washing is more rapid for hand cleansing than hand washing (True)

12.Hand rubbing causes skin dryness more than hand washing (false)

13.Hand rubbing is more effective against germs than hand washing (false)

14.Hand washing and hand rubbing are recommended to be performed in sequence (false)

15.What is the minimal time needed for alcohol-based hand rub to kill most germs on your hands?

(20 seconds)

Which type of hand hygiene method is required in the following situations?

16.Before palpation of the abdomen (rubbing)

17.Before giving an injection (rubbing)

18.After emptying a bedpan (washing)

19.After removing examination gloves (rubbing/washing

20.After making a patients bed (rubbing)

21.After visible exposure to blood (washing)

\begin{tabular}{l|l}
59 & 50.9 \\
\hline 35 & 29.7 \\
97 & 86.6 \\
\hline 37 & 30.8 \\
\hline
\end{tabular}

Which of the following should be avoided, as associated with increased likelihood of colonisation of hands with harmful germs?

22. Wearing jewellery (Yes)

23.Damaged skin (Yes)

24.Artificial fingernails (Yes)

25.Regular use of a hand cream (No)

\begin{tabular}{l|l}
10 & 8.7 \\
\hline
\end{tabular}

\begin{tabular}{|c|c|}
\hline 65 & 52.4 \\
\hline 50 & 39.4 \\
\hline 123 & 96.9 \\
\hline 128 & 99 \\
\hline 26 & 20.5 \\
\hline 120 & 94.5 \\
\hline
\end{tabular}

\begin{tabular}{l|r}
\hline 04 & 84.6 \\
\hline 101
\end{tabular}

101

120

Table 3: Overall Knowledge Score On Hand Hygiene by Respondents'

\begin{tabular}{|c|c|c|}
\hline Knowledge & Frequency & Percent $(\%)$ \\
\hline Good $(>70 \%)$ & 25 & 19.3 \\
\hline Fair $(50-69.9 \%)$ & 66 & 51.2 \\
\hline Poor $(<50 \%)$ & 38 & 29.5 \\
\hline
\end{tabular}

Table 4: Self-reported Practices of Hand Hygiene by Respondents'

\begin{tabular}{|c|c|c|c|c|c|}
\hline Variable & Always & Most of the time & Sometimes & Never & Total \\
\cline { 2 - 6 } & $n(\%)$ & $n(\%)$ & $n(\%)$ & $n(\%)$ & $N$ \\
\hline I miss out hand hygiene because I forget & $0(0.0)$ & $8(6.5)$ & $64(52.0)$ & $51(41.5)$ & 123 \\
\hline Hand hygiene makes it difficult to carry it out & $2(1.7)$ & $15(12.4)$ & $51(42.1)$ & $53(43.8)$ & 121 \\
\hline Infection prevention notices reminds us of hand hygiene & $20(16.4)$ & $20(16.4)$ & $44(36.1)$ & $38(31.1)$ & 122 \\
\hline Have more important things to do than hand hygiene & $1(0.8)$ & $9(7.4)$ & $31(25.4)$ & $81(66.4)$ & 122 \\
\hline Wearing gloves reduces the need for hand hygiene & $3(2.5)$ & $11(9.1)$ & $39(32.2)$ & $68(56.2)$ & 121 \\
\hline Emergencies makes hand hygiene difficult & $6(5.0)$ & $23(19.0)$ & $62(51.2)$ & $30(24.8)$ & 121 \\
\hline Washing hands after defecating & $108(88.5)$ & $6(4.9)$ & $5(4.1)$ & $3(2.3)$ & 122 \\
\hline Hand washing before meals & $108(88.5)$ & $8(6.6)$ & $4(3.3)$ & $2(1.6)$ & 122 \\
\hline Hand washing after meals & $94(76.4)$ & $10(8.1)$ & $16(13.0)$ & $3(2.4)$ & 123 \\
\hline
\end{tabular}




\section{International Journal of Science and Research (IJSR) \\ ISSN (Online): 2319-7064}

Index Copernicus Value (2013): 6.14 | Impact Factor (2015): 6.391

Table 5: Hand Hygiene Practices by Respondents'

\begin{tabular}{|c|c|c|}
\hline Variable & $\begin{array}{c}\text { Frequency } \\
(n)\end{array}$ & $\begin{array}{c}\text { Percent } \\
(\%)\end{array}$ \\
\hline \multicolumn{3}{|c|}{ Factors influencing hand hygiene practices } \\
\hline Inadequate water & 86 & 21.9 \\
\hline Absence of detergent & 51 & 13.0 \\
\hline Unavailability of sinks & 25 & 6.4 \\
\hline Sink leakage & 31 & 7.9 \\
\hline Sink too far & 32 & 8.2 \\
\hline Lack of clean towels & 59 & 15.1 \\
\hline Lack of hand lotion & 45 & 11.5 \\
\hline Lack of air dryer & 55 & 14.0 \\
\hline Others & 8 & 2.0 \\
\hline \multicolumn{3}{|l|}{ Reasons for not practicing hand hygiene } \\
\hline Lack of time & 38 & 17.9 \\
\hline Forgetfulness & 50 & 23.6 \\
\hline Heavy patient load & 71 & 33.5 \\
\hline Non conducive atmosphere & 31 & 14.6 \\
\hline Not knowledgeable in hand washing & 17 & 8.0 \\
\hline Others & 5 & 2.4 \\
\hline \multicolumn{3}{|c|}{ Techniques commonly used for hand hygiene } \\
\hline Use of warm running water & 18 & 5.3 \\
\hline Use of cold running water & 93 & 27.3 \\
\hline Use of soapy water in a basin & 14 & 4.1 \\
\hline $\begin{array}{l}\text { Rubbing soap on wet hands for } 20 \text { mins } \\
\text { before rinsing }\end{array}$ & 69 & 20.2 \\
\hline Use of alcohol-based hand rub & 78 & 22.9 \\
\hline Personal hand sanitizer & 69 & 20.2 \\
\hline \multicolumn{3}{|l|}{ Hand drying technique frequently used } \\
\hline Allow hands to dry on their own & 46 & 19.3 \\
\hline Use of common towels & 72 & 30.3 \\
\hline Use of disposable paper towels & 25 & 10.9 \\
\hline Use of personal handkerchiefs & 50 & 21.0 \\
\hline Use of air dryer & 34 & 14.3 \\
\hline None & 10 & 4.2 \\
\hline
\end{tabular}

Table 6: Association between Respondents' Professional status, Departments and their hand hygiene knowledge score

\begin{tabular}{|c|c|c|c|c|c|c|}
\hline \multirow[t]{2}{*}{ Variable } & $\begin{array}{c}\text { Good } \\
(>70 \%)\end{array}$ & \begin{tabular}{|c|} 
Fair \\
$(50-$ \\
$69.9 \%)$
\end{tabular} & $\begin{array}{c}\text { Poor } \\
(<50 \%)\end{array}$ & \begin{tabular}{|l} 
Total \\
Sample
\end{tabular} & $\begin{array}{l}\text { Chi- } \\
\text { square } \\
\left(X^{2}\right)\end{array}$ & $\begin{array}{c}\mathrm{P}- \\
\text { value }\end{array}$ \\
\hline & n (\%) & n (\%) & n (\%) & $\mathrm{N}$ & & \\
\hline \multicolumn{7}{|l|}{$\begin{array}{c}\text { Professional } \\
\text { status }\end{array}$} \\
\hline Nurses & $6(11.1)$ & $\begin{array}{c}27 \\
(50.0)\end{array}$ & $\begin{array}{c}21 \\
(38.9)\end{array}$ & 54 & 37.609 & 0.005 \\
\hline House officer & $5(23.8)$ & $\begin{array}{c}13 \\
(61.9)\end{array}$ & $\begin{array}{c}3 \\
(14.3)\end{array}$ & 21 & & \\
\hline Midwife & $3(23.1)$ & \begin{tabular}{|c|}
5 \\
$(38.5)$ \\
\end{tabular} & $\begin{array}{c}5 \\
(38.5)\end{array}$ & 13 & & \\
\hline Medical officer & $6(60.0)$ & $\begin{array}{c}4 \\
(40.0) \\
\end{array}$ & $0(0.0)$ & 10 & & \\
\hline Lab Scientist & $0(0.0)$ & $\begin{array}{c}5 \\
(55.6)\end{array}$ & $\begin{array}{c}4 \\
(44.4)\end{array}$ & 9 & & \\
\hline Others & $0(0.0)$ & \begin{tabular}{|c|}
5 \\
$(71.4)$
\end{tabular} & $\begin{array}{c}2 \\
(28.6)\end{array}$ & 7 & & \\
\hline Ward Assistant & $0(0.0)$ & $\begin{array}{c}3 \\
(50.0) \\
\end{array}$ & $\begin{array}{c}3 \\
(50.0) \\
\end{array}$ & 6 & & \\
\hline Physiotherapist & $2(50.0)$ & \begin{tabular}{|c|}
2 \\
$(50.0)$
\end{tabular} & $0(0.0)$ & 4 & & \\
\hline $\begin{array}{l}\text { Specialist/ } \\
\text { Consultant }\end{array}$ & $1(33.3)$ & $\begin{array}{c}2 \\
(66.7)\end{array}$ & $0(0.0)$ & 3 & & \\
\hline Anaesthetist & $2(100)$ & $0(0.0)$ & $0(0.0)$ & 2 & & \\
\hline \multicolumn{7}{|l|}{ Departments } \\
\hline Emergency & $4(22.2)$ & $\begin{array}{c}7 \\
(38.9) \\
\end{array}$ & $\begin{array}{c}7 \\
(38.9) \\
\end{array}$ & 18 & 18.454 & 0.390 \\
\hline Paediatrics & $3(16.7)$ & 11 & 4 & 18 & & \\
\hline
\end{tabular}

\begin{tabular}{|c|c|c|c|c|c|c|}
\hline & & $(61.1)$ & $(22.2)$ & & & \\
\hline Outpatient Dept. & $3(16.7)$ & $\begin{array}{c}8 \\
(44.4)\end{array}$ & $\begin{array}{c}7 \\
(38.9)\end{array}$ & 18 & & \\
\hline Obstetrics & $5(33.3)$ & $\begin{array}{c}6 \\
(40.0)\end{array}$ & $\begin{array}{c}4 \\
(26.7)\end{array}$ & 15 & & \\
\hline Others & $1(7.7)$ & $\begin{array}{c}10 \\
(76.9)\end{array}$ & $\begin{array}{c}2 \\
(15.4)\end{array}$ & 13 & & \\
\hline Surgery & $3(25.0)$ & $\begin{array}{c}8 \\
(66.7)\end{array}$ & $1(8.3)$ & 12 & & \\
\hline Laboratory & $0(0.0)$ & $\begin{array}{c}6 \\
(54.5)\end{array}$ & $\begin{array}{c}5 \\
(45.5)\end{array}$ & 11 & & \\
\hline $\begin{array}{c}\text { Mixed } \\
\text { Medical/Surgical }\end{array}$ & $2(20.0)$ & $\begin{array}{c}4 \\
(40.0)\end{array}$ & $\begin{array}{c}4 \\
(40.0)\end{array}$ & 10 & & \\
\hline ICU & $2(40.0)$ & $\begin{array}{c}3 \\
(60.0)\end{array}$ & $0(0.0)$ & 5 & & \\
\hline $\begin{array}{c}\text { Internal } \\
\text { medicine }\end{array}$ & $1(33.3)$ & $\begin{array}{c}2 \\
(66.7)\end{array}$ & $0(0.0)$ & 3 & & \\
\hline
\end{tabular}

\section{Discussion}

With the aim to reduce healthcare associated infections and the spread of antimicrobial resistance, the WHO launched Global Patient Safety Challenge in October 2005 Under the Slogan of 'Clean Care is Safer Care'. Our study aim to fulfill the aforementioned statement by providing useful insights into the prevailing practices of hand hygiene and major barriers to proper hand hygiene practices.

A total of 130 healthcare workers participated in the study with majority of them as nurses (41.9\%) and house-officers $21(16.3 \%)$, and majority were females (62.3\%).Though majority of the respondents' $(77.3 \%)$ have had training in hand hygiene, more than half of them $(51.2 \%)$ had fair knowledge in hand hygiene practices. This finding is consistent with other studies which shows low level knowledge in hand hygiene among healthcare workers (Pittet et al., 2000; Danchaivijtr et al., 2005; Harris et al., 2000). But majority of the respondents' knew that hand hygiene should be performed before touching a patient $(87.7 \%)$ and after touching a patient $(89.4 \%)$ which is consistent to findings in other studies (Pittet et al.,2004).

Also majority (86.6\%) knew that hand rubbing is not more effective against germs than handwashing. Less than half of the respondents' were aware of the hand hygiene method needed before giving an injection (39.4\%) and after making a patient's bed $(20.5 \%)$. Majority $(>80 \%)$ were aware that the following should be avoided as is associated with increased likelihood of colonisation of hands with harmful germs: wearing jewellery, damaged skin and artificial fingernails.

In our study,less than half $(31.1 \%)$ does not believe that infection prevention notices reminds them of hand hygiene. Also about $32.2 \%$ believes that wearing gloves sometimes reduces the need for hand hygiene. Majority of the respondents $(>70 \%)$ always washes hands after defecating, before and after meals. The top four (4) factors influencing hand hygiene practices included: inadequate water $(21.9 \%)$; lack of clean towels $(15.1 \%)$; lack of air dryer $(14.0 \%)$ and absence of detergent $(13.0 \%)$ and the top three (3) reasons for not practicing hand hygiene included: heavy patient load $(33.5 \%)$; forgetfulness $(23.6 \%)$ and lack of time $(17.9 \%)$.This findings explaining the low compliance in 


\section{International Journal of Science and Research (IJSR) \\ ISSN (Online): 2319-7064}

Index Copernicus Value (2013): 6.14 | Impact Factor (2015): 6.391

proper hand hygiene practices is consistent with other studies performed in Nigeria and Ghana (Omuemu et al., 2013; Yawson\&Hesse.,2013; Alex-Hart \&Opara,2011).

In this study, techniques commonly used by respondents' for hand hygiene are the use of cold running water $(27.3 \%)$, use of alcohol-based hand rub (22.9\%). Only $18(5.3 \%)$ were using warm running water. Hand drying techniques used included: use of common towels (30.3\%); use of personnel handkerchiefs $(21.5 \%)$; allowing hands to dry on their own $(19.3 \%)$, use of disposable towels (10.9\%). From the above, it could be seen that alcohol-based hand rubs are not much patronised by healthcare workers, maybe because of its availability or because of heavy patient load/insufficient time preventing its use or because of lack of awareness for its use in preventing transmission of germs.

Our study demonstrates that the professional status of the healthcare worker was significantly associated with hand hygiene knowledge score $(\mathrm{P}=0.005)$, but not correlated to their departments $(\mathrm{P}=0.390)$, which is inconsistent with other studies that have noticed better hand hygiene compliance among healthcare workers working in Paediatrics and Medicine departments as compared to those involved in surgical and intensive care units (Larson EA,2004;Pessosa-silva et al.,2005)).

\section{Conclusions}

Knowledge in hand hygiene practices was found to be fair, with heavy patient load, forgetfulness and unavailability of water and detergent being the major contributing factors hampering proper hand hygiene practices. Also there was low patronage for alcohol-based hand rubs and only 5.3\% had access to warm running water. A hospital-wide program aiming at healthcare workers and adoption of alcohol-based hand rubs at the point of care can help improve compliance to hand hygiene. Senior practitioners should be sensitized to act as role models of excellent hand hygiene practice to junior practitioners.

\section{References}

[1] Kusachi S, Sumiyama Y, ArimaY, Yoshida Y, Tanaka $\mathrm{H}$, NakamuraY, et al.Creating a manual for proper hand hygiene and its clinical effects. Surg Today2006; 36: 410-5.

[2] Pittet D, Hugonnet S, Harbarth S, Mourouga P, Sauvan $\mathrm{V}$, Touveneau S, et al.Effectiveness of a hospital-wide programme to improve compliance with handhygiene. Infection ControlProgramme. Lancet 2000; 356: 130712.

[3] Danchaivijtr S, Pichiensatian W, Apisarnthanarak A, Kachintorn K,Cherdrungsi R. Strategies to improve hand hygiene practices in two universityhospitals. J Med Assoc Thai 2005; 88 Suppl 10: S155-60.

[4] Akyol AD. Hand hygiene among nurses in Turkey: opinions and practices. JClinNurs 2007; 16: 431-7.

[5] Sax H, Perneger T, Hugonnet S, Herrault P, Chraiti $\mathrm{MN}$, Pittet D. Knowledgeof standard and isolation precautions in a large teaching hospital. InfectControl HospEpidemiol 2005; 26: 298-304.
[6] Harris AD, Samore MH, Nafziger R, DiRasorio K, Roghmann MC, CarmeliY. A survey on handwashing practices and opinions of healthcare workers. JHosp Infect 2000; 45: 318-21.

[7] Pittet D, Simon A, Hugonnet S, Pessoa-Silva CL, Sauvan V, Perneger TV.Hand hygiene among physicians: performance, beliefs, and perceptions. AnnIntern Med 2004; 141: 1-8.

[8] Biddle C. Semmelweis revisited: hand hygiene and nosocomial disease transmission in the anesthesia workstation.Journal of the American Association of Nurse Anesthetists A 2009;77(3):229-37.

[9] WorldHealth Organization. WHO Guidelines on hand hygiene inhealth care settings. Geneva, World HealthOrganization; 2005.

[10] Vincent JL. Nosocomial infectionsin adultintensive-care units.Lancet 2003;361:2068-77.

[11] Gosling R, Mbaita R, Savage A, Mulligan JA, Reyburn H. Prevalenceof hospital-acquired infections in a tertiary referral hospital innorthern Tanzania. Ann Trop Med Parasitol 2003;97:69-73.5.

[12] Faria S, Sodano L, Gjata A, Dauri M, Sabato AF, Bilaj $\mathrm{A}$, et al. Thefirst prevalence survey of nosocomialinfections in the UniversityHospital Centre 'Mother Teresa' of Tirana, Albania. J Hosp Infect 2007;65:244-50.

[13] Kallel H, Bahoul M, Ksibi H, Dammak H, Chelly H, Hamida CB,et al. Prevalence of hospital-acquired infections in a TunisiaHospital. J Hosp Infect 2005;59:343-7.

[14] Jroundi I, Khoudri I, Azzouzi A, Zeggwagh AA, Benbrahim NF,Hassouni F, et al. Prevalence of hospital-acquired infections in aMoroccan university hospital. Am. J Infect Control 2007;35:412-6.

[15] Pittet D. Improving compliance with hand hygiene in hospitals.Infect Control HospEpidemiol 2000;21:381-6.

[16] Owusu-Ofori A, Jennings R, Burgess J, Prasad PA, Acheampong F, Coffin SE (2010) Assessing Hand Hygiene Resources and Practices at a Large African Teaching Hospital. Infect Control HospEpidemiol 31 Suppl 8: 802-808.

[17] Asare A, Enweronu-Laryea CC, Newman MJ (2009) Hand hygiene practices in a neonatal intensive care unit in Ghana. J Infect DevCtries 3 Suppl 5: 352-356.

[18] Yawson,A.E\&Hesse,A.A. (2013) Hand hygiene practices and resources in a teaching hospital in Ghana .J Infect DevCtries2013; 7(4):338-347.

[19] Samuel R, Almedom AM, Hagos G, Albin S, Mutungi A. Promotion of handwashing as a measure of quality of care and prevention of hospital-acquired infections in Eritrea: the Keren study. African Health Sciences 2005; $5(1): 4-13$.

[20]Boyce JM. Antiseptic Technology: Access, Affordability and Acceptance. Emerg Infect Dis 2001; $7(2): 231-233$. dx.doi.org/10.3201/eid0702.010216

[21] Pittet D, Simon A, Hugonnet S, Pessoa-Silva CL, Sauvan V, Perneger TV. Hand hygiene among physicians: performance, beliefs and perception. Annals of Internal Medicine 2004; 141(1):1-38.

[22] Harris AD, Samore MH, Nafziger R, Dirosario K, Roghmann MC, Carmeli Y. A survey on handwashing 


\section{International Journal of Science and Research (IJSR) \\ ISSN (Online): 2319-7064}

Index Copernicus Value (2013): 6.14 | Impact Factor (2015): 6.391

practices and opinions of healthcare workers. The journal of hospital Infection 2000; 45(4):319-321.

[23] Patarakul K, Tau-Khum A, Kanha S, Padung-Pean D, JaichaiyapumOO.Cross-sectional survey of hand hygiene compliance and attitudes of health care workers and visitors in the intensive care units of King Chulalongkorn Memorial Hospital. J Med Assoc Thai 2005; 88 Suppl 4: S287-293.

[24] Suchitra JB, Devi NL. Impact of educationon knowledge, attitudes and practices among various categories of healthcare workers on nosocomial infections. India Journal of Medical Microbiology 2007; 25(3): 181-187

[25] Alex-Hart BA\&Opara PI. Handwashing practices amongst health workers in a teaching hospital. American Journal of Infectious Diseases 2011; 7(1):815.

[26] Grayson ML, Russo PL, Cruickshank M, Bear JL, Gee CA, Hughes CF, et al.Outcomes from the first 2 years of the Australian National Hand Hygiene Initiative. Med JAust. 2011 Nov 21;195(10):615-9.

[27] Grayson ML, Jarvie LJ, Martin R, Johnson PD, Jodoin $\mathrm{ME}$, McMullan $\mathrm{C}$, et al.Significant reductions in methicillin-resistant Staphylococcus aureusbacteraemia and clinicalisolates associated with a multisite, hand hygiene culture-change program and subsequentsuccessful statewide roll-out. Med J Aust. 2008 Jun 2;188(11):633-40.

[28] Ho ML, Seto WH, Wong LC, Wong TY. Effectiveness of multifaceted hand hygiene interventions in long-term care facilities in Hong Kong: a cluster-randomized controlled trial.Infect Control HospEpidemiol. 2012 Aug;33(8):761-7.

[29] Girou E, Legrand P, Soing-Altrach S, Lemire A, Poulain C, Allaire A, et al.Association between hand hygiene compliance and methicillin-resistant Staphylococcusaureus prevalence in a French rehabilitation hospital. Infect Control HospEpidemiol. 2006 Oct;27(10):1128-30.

[30] Trick WE, Vernon MO, Welbel SF, Demarais P, Hayden MK, Weinstein RA, etal.Multicenter intervention program to increase adherence to hand hygiene recommendationsand glove use and to reduce the incidence of antimicrobial resistance. Infect Control HospEpidemiol. 2007 Jan;28(1):42-9.

[31] Larson E. A tool to assess barriers to adherence to hand hygiene guideline. Am J Infect Control 2004; 32: 48-51.

[32] Vivian OssaidiomOmuemu, Esohe O. Ogboghodo, Rosemary A. Opene, PhebeOriarewo, OrezimenaOnibere (2013).Hand hygiene practices among doctors in a tertiary health facility in southern Nigeria.Journal of Medicine in the Tropics 15:2: 96 101

[33] Pessosa-Silva CL, Posfay-Barbe K, Pfister R, Touveneau S,Perneger TV, Pittet D.(2005) Attitudes and perceptions towards handhygiene among healthcare workers caring for critically ill neonates.Infect Control HospEpidemiol;26:305-11.

\section{Author Contributions}

I.A. was the principal author and contributed to the study concept,design, interpretation and discussion of the data. S.S contributed to the data collection and J.C. contributed towards analysis of the data. All authors read and approved the final manuscript. 